\title{
Impairment no Goodwill: Uma Análise Baseada na Divulgação Contábil de Empresas Brasileiras Listadas pela Revista Eletrônica Forbes
}

\author{
Nera Ingridy Silva Menezes ${ }^{1}$, Raimundo Nonato Lima Filho ${ }^{2}$
}

\begin{abstract}
Resumo: Este estudo objetivou verificar o nível de divulgação das informações sobre o teste de Impairment no goodwill das empresas brasileiras de capital aberto, listadas na "Global 2000" pela revista eletrônica Forbes, no período de 2011 a 2016, em relação as exigências descritas e obrigatórias do CPC 01. Pretendeu-se dar continuidade ao estudo de Barbosa et al. (2014) seguindo a mesma métrica, utilizando os mesmo itens de divulgação, permitindo obter um índice de informações divulgadas por empresa. Para tanto, analisou-se as demonstrações contábeis no grupo de ativo intangível extraídas do site da Comissão de Valores Mobiliários (CVM). Após a captação de dados, foi feita uma análise nas empresas que realizaram o reconhecimento de perda por desvalorização em relação aos itens verificados das exigências obrigatórias para divulgação do teste de Impairment no goodwill, de acordo com o CPC 01 (R1). Os resultados encontrados demonstraram uma divulgação positiva da grande maioria dos itens evidenciados durante os seis anos, com um número maior de exigências sobre o teste no último triênio. As companhias retrataram um percentual coeficiente de variação homogêneo, ou seja, houve pouca dispersão dos valores durante os anos, constatando-se uma evidenciação de média $80 \%$ das informações exigidas quanto ao teste de Impairment, de acordo com os itens da métrica designados.
\end{abstract}

Palavras-Chave: Impairment; Goodwill; Recuperabilidade; Divulgação.

\section{Impairment no Goodwill: An Analysis Based on the Accounting Disclosure of Brazilian Companies Listed on the Forbes}

\begin{abstract}
This study aimed to verify the level of disclosure of information about the Impairment test on the goodwill of the Brazilian publicly traded companies listed in the "Global 2000" by the electronic magazine Forbes, in the period from 2011 to 2016, in relation to the described and mandatory requirements of the CPC 01. It was intended to continue the study by Barbosa et al. (2014) following the same metric, using the same disclosure items, allowing to obtain an index of information disclosed per company. For this purpose, the financial statements of the intangible asset group extracted from the website of the Brazilian Securities and Exchange Commission were analyzed. After the data capture, an analysis was made in the companies that realized the impairment loss in relation to the verified items of the mandatory requirements for disclosure of the Impairment test in goodwill, in accordance with CPC 01 (R1). The results showed a positive disclosure of the great majority of items evidenced during the six years, with a greater number of requirements on the test in the last three years. The companies portrayed a percentage coefficient of homogeneous variation, that is, there was little dispersion of values during the years, evidencing an average disclosure of $80 \%$ of the information required for the Impairment test, according to the designated metric items.
\end{abstract}

Keywords: Impairment; Goodwill; Recoverability; Disclosure.

\footnotetext{
${ }^{1}$ neramenezes@ hotmail.com

2 Doutor em Controladoria e Contabilidade (USP). Doutor em Administração (UFBA)rnlfilho@ gmail.com
} 


\section{Introdução}

O processo de convergência das normas internacionais de contabilidade foi implantado no Brasil a partir de 2008, com o advento da lei 11.638/07. Nesse contexto de mudança das normas brasileiras de contabilidade, diversos pronunciamentos técnicos foram emitidos pelo Comitê de Pronunciamentos Contábeis (CPC), dentre os quais, o CPC 15 - Combinação de Negócios de 2009, estando correlacionado a Internacional Financial Reporting Standards (IFRS) 3, oriundo do Internacional Accounting Standards Board (IASB), no qual designa como principal foco o reconhecimento e mensuração do ágio por expectativa de rentabilidade futura (goodwill), objetivando o aprimoramento da relevância, da confiabilidade e da comparabilidade das informações que a entidade fornece em suas demonstrações contábeis acerca dos efeitos de combinação de negócios.

Segundo Nakayama e Salotti (2014), a combinação de negócios é uma operação em que uma empresa adquire o controle de um ou mais negócios, independentemente da forma jurídica da operação, podendo ser uma fusão ou uma obtenção de controle. Atraindo enorme interesse nos meios empresariais, pois afetam fortemente nas decisões de fornecedores, empregados e clientes relacionados com essas empresas, além das grandes cifras envolvidas.

Ainda, Vieira et al. (2017) afirmaram que o CPC 15 (R1) determina os aspectos contábeis que devem ser analisados pela empresa adquirente no que se refere à mensuração do valor justo dos ativos identificáveis e passivos assumidos e ao reconhecimento e à mensuração do ágio por expectativa de rentabilidade futura ( goodwill) ou ganho em compra vantajosa, além das informações acerca da operação que devem ser evidenciadas em notas explicativas.

Contudo, outro pronunciamento técnico que está diretamente relacionado ao CPC 15 é o CPC 04 - Ativo Intangível, estabelecendo que uma entidade deve reconhecer um ativo intangível apenas se determinados critérios especificados neste pronunciamento forem atendidos, discriminando também, como mensurar o valor contábil dos ativos intangíveis, exigindo divulgações específicas sobre esses ativos, em especial ao goodwill e sua condição ao teste de Impairment, seguindo as obrigações impostas no CPC 01 - Redução ao Valor Recuperável de Ativos.

O teste de redução ao valor recuperável assegura que o valor contábil de um ativo não seja maior do que o seu valor recuperável - VR, sendo que o VR é estimado com base no maior valor entre o valor liquido de venda e o valor em uso do ativo. O Comitê de Pronunciamentos Contábeis (CPC), por meio do pronunciamento CPC 01 (R1) de 2010, estabelece como deve 
ser realizado o teste de Impairment dos ativos, especificando como determinar o valor em uso, que envolve a escolha de uma estimativa de fluxos de caixa futuro esperados, de uma taxa de crescimento e de uma taxa de desconto, além da escolha dos ativos para o teste.

Na visão de Vogt et al. (2016) a adoção do teste de Impairment tem o objetivo de trazer uma visão mais realística para o valor do goodwill e a aplicação desse teste deve ter cuidados maiores do que para outros ativos, já que o goodwill é o único ativo não diretamente associado a direitos específicos identificáveis, e não é separável da companhia como um todo.

Alguns estudos realizados no Brasil constataram falhas na divulgação do teste de Impairment sobre a perda no valor recuperável no ativo intangível com níveis divergentes de divulgação entre empresas cujas ações são negociadas na Bolsa de Valores, Mercadorias e Futuros (BM\&FBovespa), como de Souza, Borba e Zandonai (2011), Albani e Almeida (2012), Machado, Cruz, Takamatsu e Lima (2013) e de Barbosa, Consoni, Scherer e Clemente (2014).

Diante das concepções mencionadas, a presente pesquisa busca responder à seguinte questão: Qual é o nível de divulgação do teste de Impairment no goodwill pelas empresas brasileiras de capital aberto, listadas pela Forbes, em relação a exigências do CPC 01? Tendo como objetivo, verificar o nível de divulgação das informações sobre o teste de Impairment no goodwill das empresas brasileiras de capital aberto, listadas na "Global 2000" pela revista eletrônica Forbes, no período de 2011 a 2016, em relação as exigências descritas e obrigatórias do CPC 01.

Sendo assim, o presente estudo longitudinal apresenta uma análise do nível de evidenciação do teste de Impairment no goodwill nas empresas de capital aberto do Brasil, listadas pela Forbes, no período após a criação do CPC 01, ao longo de 2011 a 2016. Tendo por base metodológica o estudo de Barbosa et al. (2014), que utiliza uma métrica composta por itens, para análise do nível de divulgação do reconhecimento de perda e a evidenciação dos procedimentos de realização do teste de Impairment no goodwil.

Por conseguinte, justifica-se que em períodos de crise a evidenciação justa do Impairment no goodwill pode causar efeitos relevantes na estrutura financeira das empresas, principalmente em seus resultados. Com isso, os resultados obtidos neste estudo podem contribuir para o melhor conhecimento sobre o tratamento contábil e divulgação do teste de Impairment no goodwill, pelas empresas brasileiras de capital aberto, e permitir uma análise da evidenciação e identificação dos benefícios futuros desses ativos logo após o seu reconhecimento inicial. 
A segunda seção deste estudo é destinada ao referencial teórico com destaque para o teste de Impairment, goodwill e ao CPC 01. A terceira seção destina-se à metodologia com a definição da população, amostra e a descrição dos métodos de análise de dados. Na quarta seção é apresentada a análise e discussão dos resultados obtidos. Finalmente, na quinta seção apresentam-se as considerações finais, as limitações do estudo e as pistas para pesquisas futuras.

\section{Revisão de Literatura}

\section{Teste de Impairment}

O Impairment é uma palavra de origem inglesa, que ao traduzida para o português detém significados de prejuízo, dano, enfraquecimento e deterioração. Segundo Tavares et al. (2010), o seu conceito em termos contábeis equivale a de redução ao valor recuperável de ativos. Onde para Souza, Borba e Dutra (2008), o termo Impairment, contabilmente, significa redução de capital ou descapitalização, atestando como finalidade a verificação de que o valor contábil corresponde à capacidade de geração de benefícios econômicos futuros do ativo.

No Brasil, o Impairment test foi aprovado pela Comissão de Valores Mobiliários (CVM) por meio da Deliberação n ${ }^{\circ}$ 27/2007, tornando obrigatória a sua realização e divulgação para todas as companhias abertas, a partir de 31 de dezembro de 2008. Com a promulgação da Lei 11.638/2007, o teste de Impairment foi regulado pelo CPC 01 - Redução ao Valor Recuperável de Ativos, que em 2010 passou por uma revisão e normatização pela Deliberação nº . 639/10 da CVM.

Nessa perspectiva, os estudos pioneiros no Brasil surgiram em 2008, quando Smith et al. (2008) analisaram o impacto sofrido pelos indicadores econômicos e financeiros de desempenho pela prática do Impairment test e se de alguma maneira pode desencadear uma estratégia para melhorar os indicadores. Concluíram que o reconhecimento da perda ocasiona um aumento nos indicadores.

Na sequência, o estudo empírico de Tavares et al. (2010), analisou se as empresas de capital aberto evidenciaram a perda por Impairment no ativo imobilizado e intangível através de suas notas explicativas divulgadas em 2008, indicando que nenhuma das empresas do mercado de capitais brasileiro divulgou plenamente a perda por Impairment determinado pelo CPC 01, no primeiro ano de sua adoção. 
Já Reis et al. (2013) desenvolveram um estudo no setor siderúrgico brasileiro sobre o grau de evidenciação das informações relativas ao valor recuperável de seus ativos fixos. Com informações levantadas nos demonstrativos contábeis das empresas deste setor, listadas na BM\&FBovespa, no triênio 2008-2010. Revelando no estudo a falta de adequabilidade das informações evidenciadas exigidas pelo CPC 01, onde as empresas do setor estavam apresentando demonstrações contábeis com caráter mais descritivo do que explicativo, demonstrando-se como uma réplica do CPC 01.

Bianchi et al. (2015), investigaram o nível de evidenciação do Impairment test dos ativos imobilizado e intangível, das empresas que compõem o índice IBrX-100 da BM\&FBOVESPA entre os anos de 2011 a 2013. Concluindo um índice muito baixo de empresas que evidenciam em seus relatórios contábeis o Impairment test. Porém, percebeu- se que a maioria das empresas começou atendendo as normas de evidenciação, mas por alguma razão, o nível de evidenciação estagnou.

Como pode ser visto, apesar do desenvolvimento crescente da literatura sobre o Impairment no mercado de capitais, em geral, os resultados dos estudos empíricos anteriores mais recentes, evidenciam um baixo nível de divulgação do teste de Impairment, em desacordo com as normas internacionais de contabilidade divulgadas através do CPC 01, o que evidencia um problema de assimetria informacional neste contexto.

\section{Goodwill}

O goodwill é conceituado pelo Pronunciamento Técnico CPC 04 como o "ágio por expectativa de rentabilidade futura reconhecido em uma combinação de negócios, o qual representa benefícios econômicos futuros gerados por ativos adquiridos que não são reconhecidos individualmente”. Por sua vez, o CPC 15 - Combinação de Negócios define que o "goodwill é um ativo que representa benefícios econômicos futuros resultantes dos ativos adquiridos em combinação de negócios, os quais não são individualmente identificados e separadamente reconhecidos" (CPC, 2011).

Schmidt e Santos (2009) contribuem com esta visão quando declaram que o conceito, a forma de avaliação e sua natureza do goodwill, fazem dele, um dos temas mais complexos da contabilidade. 
O primeiro trabalho direcionado no goodwill, segundo Cavalinhos e Carreira (2015) surgiu em 1891, por Francis More, num artigo publicado na revista The Accountant William Harris, o qual analisou o goodwill, firmado em diferentes opiniões e critérios.

No Brasil, mais de um século depois, Martins et al. (2010) realizaram um estudo sobre o conceito de goodwill utilizado no desenvolvimento de pesquisas publicadas nos principais periódicos internacionais e nacionais. Os autores concluíram que do total de trabalhos com o conceito de goodwill explícito, 18 apresentam conceito divergente daquele definido pela literatura contábil. Destacaram ainda que $61 \%$ dos erros desses trabalhos se referem ao cálculo do goodwill como sendo a diferença entre o valor de mercado e o valor contábil do patrimônio.

Por sua vez, para certificar se as expectativas de rentabilidade futura serão realizadas após a aquisição, o CPC 01 (2010) afirma que deve ser efetuado o teste de Impairment, pelo menos uma vez por ano, em qualquer hipótese. Devendo reconhecer, se houver, a perda por Impairment no goodwill, no resultado do exercício e, ao contrário dos demais ativos, sem possibilidade de reversão em período posterior. A realização do teste de Impairment no goodwill foi prevista desde 2008, mas, apenas em 2009, com a Deliberação n. 580/2009, a CMV exigiu tal procedimento.

A partir do CPC 01, diversos estudos como de Barbosa et al. (2014) e Gomes et al. (2017), propuseram investigações sobre o Impairment test no goodwill.

Barbosa et al. (2014), verificaram se as empresas brasileiras de capital aberto divulgaram informações sobre o teste de Impairment no goodwill, no período de 2009 a 2011. Os resultados indicaram que em 2009 a maioria das empresas não evidenciou nenhuma informação exigida para o teste de Impairment no goodwill. No entanto, em 2010 e 2011, o percentual de empresas que nada evidenciaram sobre os procedimentos adotados para o teste decresceu. Aliado a isto, apontaram que o índice de evidenciação, em média, aumentou no decorrer do período analisado.

Nesta linha de investigação, Gomes et al. (2017) investigaram se as empresas listadas no segmento 'Novo Mercado' estão procedendo quanto às exigências de divulgação do Impairment no Goodwill definidas no CPC 01 (R1). Chegando ao resultado que, embora algumas empresas apresentem pouca evidenciação de informações do teste de recuperabilidade, houve melhora na divulgação se comparados aos achados da pesquisa desenvolvida por Barbosa et al. (2014). Os autores destacaram que todas as empresas alvo da pesquisa efetuaram o teste, resultado diferente do encontrado em pesquisas anteriores, representando um avanço ao passar dos anos. 


\section{CPC 01 - Redução ao Valor Recuperável de Ativos}

A Impairment of Assets (IAS) 36 faz parte de um conjunto de regulamentações emitidas pelo International Accounting Standards Board (IASB) com a concepção de padronização das políticas contábeis, a fim de aumentar a conformidade das informações contábeis a nível global. O objetivo da norma é assegurar que seus ativos estejam registrados contabilmente por valor que não exceda seus valores de recuperação (CPC 01).

O pronunciamento técnico CPC 01 foi constituído através das alterações na Lei ${ }^{\circ}$ 6.404/76 por meio das Leis $\mathrm{n}^{\circ} 11.638 / 07$ e 11941/09, com a convergência às normas internacionais, sendo que a Lei $\mathrm{n}^{\circ} 11.638 / 07$ faz referência à análise sobre o valor recuperável registrado no imobilizado e no intangível.

Segundo o IAS 36, deve-se testar anualmente a redução no valor recuperável de um ativo intangível com vida útil indefinida ou de um ativo intangível ainda não disponível para uso, comparando o seu valor contábil com o seu valor recuperável. Se ocorrer o inverso, uma reavaliação, a legislação brasileira (Lei 11.638/07) proíbe esse tipo de procedimento em ativos, o que difere internacionalmente, pois a reavaliação pelas normas contábeis internacionais (IFRS - International Financial Reporting Standard) é permitida.

Em estudo empírico sobre a evidenciação do teste de Impairment, Souza (2011) verificou que as empresas que reconheceram perda por Impairment em 2008 e 2009, inclusive sobre o goodwill, não informaram, principalmente, a base utilizada no cálculo do teste, nem tampouco a taxa de desconto utilizada. Além disso, Souza (2011) constatou que as empresas com menores índices de rentabilidade apresentaram um maior nível de evidenciação do teste de Impairment.

Já em outro estudo, Souza, Borba e Zandonai (2011) enfatizaram que dependendo do valor, o reconhecimento de uma perda pode causar grande impacto no resultado do exercício. Por outro lado, afirmaram que do ponto de vista gerencial, a constatação desta deficiência pode representar uma alternativa de mudanças positivas para a empresa, apesar da redução no resultado, servindo de alerta para a mesma revisar sua política de aplicação de recursos em ativos.

\section{Procedimentos Metodológicos}

Nesta seção apresenta-se a metodologia aplicada a este estudo, organizada em dois tópicos: A composição da amostra e apresentação da população utilizada; e em seguida são 
apontados os procedimentos metodológicos aplicados, apresentando os instrumentos utilizados na coleta de dados.

\section{População}

Quanto aos fins, este estudo caracteriza-se como exploratório e descritivo, com uma abordagem quantitativa e qualitativa. Quanto aos meios, trata-se de uma análise documental do conteúdo da divulgação do teste de Impairment no goodwill através das demonstrações contábeis das empresas de capital aberto. A população é composta pelas maiores empresas brasileiras de capital aberto classificadas pela revista Forbes, nas edições do Global 2000. A amostra analisada é constituída pelas empresas listadas no ranking Forbes, com registro ativo em todos os anos do período analisado de 2011 a 2016. Esse período objetiva analisar o grau de evidenciação do teste de Impairment no goodwill, no período após a revisão do CPC 01(R1) em 2010, com vigência a partir de 2011.

A Global 2000, seleciona dados interativos, fundamentados da Thomson Reuters e bancos de dados do Worldscope através dos Sistemas de Pesquisa FactSet para empresas que negociavam publicamente. Selecionando as maiores empresas em quatro métricas separadas das 2000 maiores empresas: vendas, lucros, ativos e valor de mercado, incluindo todas as ações ordinárias em circulação. A lista tem um valor de corte mínimo para que uma empresa se qualifique. Uma empresa precisa se qualificar para pelo menos uma das listas para ser elegível para o ranking final do Global 2000 (FORBES, 2011).

A amostra é constituída pelas empresas listadas no ranking durante todos os anos (de 2011 a 2016) que possuem registro ativo nos seis anos descritos. Constituídas inicialmente por 13 empresas com continuidade, as quais são a PETROLEO BRASILEIRO S.A. PETROBRAS, BCO BRADESCO S.A., BCO BRASIL S.A., VALE S.A., ITAUSA, CSN CIA SIDERURGICA NACIONAL, CENTRAIS ELET BRAS S.A. - ELETROBRAS, CIA ENERGETICA DE MINAS GERAIS - CEMIG, GERDAU S.A., JBS S.A., BRASKEM S.A., BRF S.A. e CIELO S.A.

A coleta de dados para exame documental foi efetuada através das informações contábeis do Balanço Patrimonial e Nota Explicativa do grupo intangível das empresas incluídas na amostra, divulgadas através do sítio eletrônico da CVM e da BM\&FBovespa. 


\section{Métodos da Pesquisa}

Para analisar o nível de divulgação do teste de Impairment no goodwill das empresas incluídas na amostra, foi utilizada uma métrica composta por 13 itens com base nas principais exigências de divulgação do CPC 01, de forma semelhante à Barbosa et al. (2014). Os requisitos são referentes a evidenciação dos procedimentos de realização do teste de Impairment no goodwill, o qual é obrigatório pelo menos anualmente, e ao reconhecimento de perda (Tabela $1)$.

Tabela 1 - Exigências obrigatórias para divulgação do teste de Impairment no goodwill, de acordo com o CPC 01 (R1)

\begin{tabular}{c|l}
\hline Item & \multicolumn{1}{c}{ Exigências } \\
\hline 1 & Valor da perda para Unidade Geradora de Caixa (segmento, linha de produtos, etc.) \\
\hline 2 & Linha na DRE na qual a perda foi incluída \\
\hline 3 & Eventos ou circunstâncias que levaram ao reconhecimento da perda \\
\hline 4 & A base de cálculo, se valor em uso ou valor justo \\
\hline 5 & Descrição da Unidade Geradora de Caixa \\
\hline 6 & Informar o método utilizado no cálculo do valor recuperável \\
\hline 7 & A taxa de desconto utilizada na estimativa corrente \\
\hline 9 & Descrição das premissas-chave que serviram de base para o cálculo \\
\hline 10 & $\begin{array}{l}\text { Descrição da abordagem para determinar os valores alocados a cada premissa-chave } \\
\text { (se refletem a experiência passada ou se estão assentadas em informações externas) }\end{array}$ \\
\hline 11 & Especificar o período (em anos) sobre o qual a administração projetou o fluxo de caixa \\
\hline 12 & A taxa de crescimento utilizada para extrapolar as projeções de fluxo de caixa \\
\hline 13 & Os reflexos decorrentes de uma possível mudança na premissa-chave \\
\hline *Não está constando tábil do goodwill as exigências. alocado à Unidade Geradora de Caixa \\
Fonte: Adaptado de Barbosa et al. (2014), baseado no CPC 01(R1) (2010).
\end{tabular}

Para verificar se houve a realização do teste de Impairment no goodwill e, eventualmente, o reconhecimento de perda, foi lida na integra a Nota Explicativa do intangível e verificado o balanço patrimonial das 13 empresas citadas. Ainda, foram utilizadas as seguintes palavras-chave: Impairment; recuperável, goodwill e divulgação. Possibilitando obter informações em seções mais específicas das Notas Explicativas.

Para codificar a dinâmica, foi atribuído o valor igual a 1, para cada item evidenciado e 0, caso contrário. Para obter o percentual de atendimento aos itens das exigências, foi dividida a soma dos pontos de cada empresa pelo total de itens. 


\section{Análise dos Resultados da Pesquisa}

Das 13 empresas utilizadas como amostra, apenas a Gerdau apresentou goodwill registrado no balanço patrimonial durante o período analisado. A JBS apresentou nos anos de 2014 a 2016, já a Petrobras apenas no primeiro triênio (2011-2013). Por conseguinte, todas as companhias informaram em suas notas explicativas, a realização do teste de recuperabilidade do ágio anualmente e sempre que for observado um evento que cause a redução ao valor recuperável, comparando o valor recuperável da Unidade Geradora de Caixa (UGC) com o valor contábil de seus ativos líquidos, contabilizado ao custo deduzido das perdas acumuladas por redução ao valor recuperável, enfatizando ainda que perdas por redução ao valor recuperável de ágio não podem ser revertidas. Com isso, onze das treze empresas analisadas não identificaram a necessidade do Impairment, não deixando de proceder o teste anualmente nesse ativo, de acordo com o que pede o CPC 01.

As companhias que realizaram o teste e a divulgação de perda por desvalorização do ativo foram o Banco Bradesco S.A (mesmo não apresentando goodwill em seu balanço patrimonial durante os seis anos, realizou a divulgação referentes a valores anteriores) e a Gerdau S.A.

Os resultados da análise de conteúdo demonstraram que o Banco Bradesco S.A. reconheceu as perdas por Impairment dos ativos intangíveis "aquisição de direitos bancários" e "software", na demonstração de resultado e no balanço patrimonial, bem como evidenciou tais perdas em suas notas explicativas em todo o período analisado, em função do valor recuperável dos referidos ativos ter sido inferior ao seu valor contábil. As perdas por redução ao valor recuperável foram reconhecidas no resultado, na rubrica "Outras receitas/(despesas) operacionais".

A Gerdau S.A. reconheceu perdas por redução ao valor recuperável nos anos de 2014, 2015 e 2016. Em dezembro de 2011, 2012 e 2013 a companhia avaliou a recuperabilidade do ágio dos seus segmentos e os testes efetuados não identificaram perdas pela não recuperabilidade do ágio no exercício.

Já em dezembro de 2014, os testes realizados identificaram perdas pela não recuperabilidade de ativos no segmento América Latina no montante de R \$339.374 em virtude de falta de expectativa de utilização futura destes ativos. Enfatizando que em determinados cenários de sensibilidade a companhia identificou risco mais elevado de que, havendo 
deteriorações de determinados fundamentos econômicos, e que ajustes possam vir a ser requeridos em exercícios futuros.

Em 2015 a companhia Gerdau S.A. concluiu pela antecipação do teste de recuperabilidade de ágio e outros ativos de vida longa para o terceiro trimestre de 2015, no qual foram identificadas perdas pela não recuperabilidade de ativos no montante de $\mathrm{R} \$ 1.867 .586$, sendo $\mathrm{R} \$ 1.161 .688$ como resultado do teste de recuperabilidade de outros ativos de vida longa e R 705.898 como resultado do teste de recuperabilidade do ágio. Durante o quarto trimestre de 2015, a companhia verificou uma deterioração das condições econômicas de alguns mercados consumidores de aço numa intensidade maior do que aquela contemplada nos cenários dos testes de recuperabilidade realizados no trimestre anterior. Estas circunstancias resultaram num aumento da taxa de desconto utilizadas nas projeções dos fluxos de caixa de seus segmentos de negócio. A companhia, então, concluiu pela necessidade de realizar o teste de recuperabilidade de ágio e outros ativos de vida longa para o quarto trimestre de 2015.

Em 2016, com base nos eventos mencionados anteriormente, notadamente a deterioração das condições econômicas refletidas na queda da margem EBITDA, as análises efetuadas identificaram uma perda pela não recuperabilidade do ágio no montante de $\mathrm{R} \$$ 2.678.582 para o segmento América do Norte. Ainda, foi informada que nesse período os demais segmentos não apresentaram perda pela não recuperabilidade de ágio.

Em relação aos itens verificados das exigências obrigatórias para divulgação do teste de Impairment no goodwill, de acordo com o CPC 01 (R1), foi feita uma análise nas empresas que realizaram o reconhecimento de perda por desvalorização, mas que não necessariamente possuísse goodwill em seu balanço patrimonial.

Ao longo do período analisado, a divulgação da grande maioria dos itens evidenciados durante os seis anos é bastante positiva. Contudo, houve um número maior de exigências sobre o teste de Impairment no goodwill nos anos de 2014 a 2016, pois nos três primeiros anos existiu uma queda em relação ao item 4, no qual trata-se da informação da base de cálculo em valor em uso ou justo, como também nos itens 10 e 12, onde especifica o período (em anos) de projeção o fluxo de caixa; e os reflexos decorrentes de uma possível mudança da premissachave, respectivamente. Contudo, observa-se que o item 13 não foi divulgado em nenhum dos anos analisados (Figura 1). 


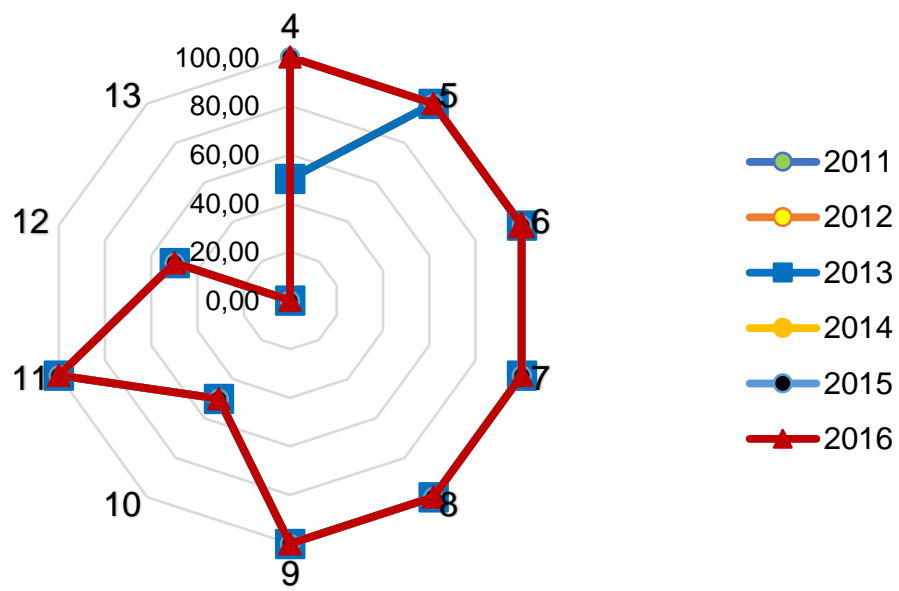

Figura 1. Percentual de divulgação dos itens 4 a 13 da métrica. Fonte: Elaborada pela autora (2018)

O item 10 é um dos principais parâmetros de influência para a definição e cálculo do valor de perda, pois trata-se de evidenciar o período de projeção do fluxo de caixa e, contudo, a companhia Bradesco S.A. não apresentou essa exigência, falhando nos seis anos analisados. Já o valor contábil do goodwill alocado a UGC (item 13), não foi apresentado em nenhuma das companhias no período, afetando assim na reflexão sobre a forma pela qual a entidade gerencia suas operações e com a qual o ágio estaria naturalmente associado.

Tabela 2- Estatística descritiva dos percentuais de evidenciação.

\begin{tabular}{c|c|c|c|c|c|c}
\hline & $\mathbf{2 0 1 1}$ & $\mathbf{2 0 1 2}$ & $\mathbf{2 0 1 3}$ & $\mathbf{2 0 1 4}$ & $\mathbf{2 0 1 5}$ & $\mathbf{2 0 1 6}$ \\
\hline Média & 0,75 & 0,75 & 0,75 & 0,8 & 0,8 & 0,8 \\
\hline Mediana & 1 & 1 & 1 & 1 & 1 & 1 \\
\hline Desvio-Padrão & 0,466 & 0,466 & 0,466 & 0,422 & 0,422 & 0,422 \\
\hline Coeficiente de variação & 0,185 & 0,185 & 0,185 & 0,178 & 0,178 & 0,178 \\
\hline Mínimo & 0 & 0 & 0 & 0 & 0 & 0 \\
\hline Máximo & 100 & 100 & 100 & 100 & 100 & 100 \\
\hline Companhias & 2 & 2 & 2 & 2 & 2 & 2 \\
\hline
\end{tabular}

Os resultados apontados na Tabela 2 retratam que o percentual de coeficiente de variação apresentado pelas companhias está homogêneo, com pouca variação por triênio, permanecendo com $185 \%$ no primeiro e com uma pequena queda de $7 \%$ no segundo (178\%) triênio. O desvio-padrão nos primeiros seis anos indica que, em relação a média, o percentual de evidenciação é uniforme, com mínimo de variação, pois mesmo as empresas que deixaram 
de divulgar algum item, apresentaram no mínimo $75 \%$ dos itens da métrica, evidenciando a maioria as exigências selecionadas.

Como o coeficiente de variação apresenta uma divulgação homogênea, reduzindo de uma forma mínima de um triênio para o outro, é retratada uma menor dispersão em torno da média que ao contrário desse coeficiente, aponta um aumento mínimo nos anos de 2014 a 2016, comparado aos anos anteriores.

Com isso, no último triênio (2014, 2015 e 2016) é constatado que as duas companhias analisadas evidenciaram $80 \%$ das informações exigidas quanto ao teste de Impairment, de acordo com os itens da métrica designados.

Essas evidências contradizem com os resultados encontrados em outros estudos, como de Avelino, Pinheiro e Lamounier (2012), apontando que há deficiências, no Brasil, no cumprimento de certos requisitos de divulgação obrigatória, como, por exemplo, de critérios de reconhecimento, mensuração e evidenciação do ativo intangível. Como também no estudo de Souza, Borba e Zandonai, em 2011, indicando a insuficiência das empresas brasileiras em apresentar do reconhecimento da perda no valor recuperável do imobilizado e do intangível.

Mesmo com os índices mostrando-se homogêneos, verificou-se a adequação das companhias da amostra as exigências de evidenciação do teste de Impairment no goodwilll em relação a proporção desse ativo no grupo intangível (GI) e no ativo total (GA). Contudo, como já exposto, a companhia Bradesco S.A. não apresentou valor de goodwill em seu Balanço Patrimonial nos últimos seis anos (2011 a 2016). Sendo assim, foram utilizados da companhia Gerdau S.A. os valores de cada uma dessas variáveis como condiz a Tabela 3.

Tabela 3 - Proporção do goodwill no grupo intangível (GI) e no ativo total (GA).

\begin{tabular}{c|c|c|c|c|c|c}
\hline GERDAU S.A. & $\mathbf{2 0 1 1}$ & $\mathbf{2 0 1 2}$ & $\mathbf{2 0 1 3}$ & $\mathbf{2 0 1 4}$ & $\mathbf{2 0 1 5}$ & $\mathbf{2 0 1 6}$ \\
\hline $\begin{array}{c}\text { Ativo intangível } \\
\text { (GI) }\end{array}$ & 10.429 .497 & 11.397 .812 & 12.850 .964 & 14.103 .502 & 16.960 .191 & 10.789 .957 \\
\hline Ativo total (GA) & 49.981 .794 & 53.093 .158 & 58.215 .040 & 63.042 .330 & 70.094 .709 & 54.635 .141 \\
\hline $\begin{array}{c}\text { Goodwill } \\
\text { Percentual - } \\
\text { goodwill / GI }\end{array}$ & 9.155 .789 & 10.033 .396 & 11.353 .045 & 12.556 .404 & 15.124 .430 & 9.470 .016 \\
\hline $\begin{array}{c}\text { Percentual - } \\
\text { goodwill / GA }\end{array}$ & $18,32 \%$ & $88,03 \%$ & $88,34 \%$ & $89,03 \%$ & $89,18 \%$ & $87,77 \%$ \\
\hline & $18,90 \%$ & $19,50 \%$ & $19,92 \%$ & $21,58 \%$ & $17,33 \%$ \\
\hline
\end{tabular}

A Gerdau S.A. manifesta uma expressiva representatividade de goodwill em relação ao ativo intangível. Na companhia, o goodwill representa mais de $80 \%$ do intangível durante os seis anos consecutivos, ou seja, o seu Ativo Intangível (GI) é formado basicamente pelo ágio 
por expectativa de rentabilidade futura (goodwill). Já em relação ao Ativo total (GA) a média do goodwill é retratada em torno de $19 \%$ do grupo.

A baixa representatividade do goodwill no ativo total pode ser por motivos de que a empresa não tenha incentivos para divulgação se o eventual reconhecimento da perda não prejudicar a condução dos negócios (BARBOSA et al.,2014). Ainda segundo os autores, a diversificação das atividades produtivas ou comerciais e fontes de financiamento também pode interferir na representatividade, principalmente em relação as características do mercado em que a empresa atua.

Seguindo essa linha, para tentar entender o porquê da baixa representatividade do goodwill no ativo total, foi observado o comportamento retratado pelas duas companhias da amostra em relação a divulgação do teste de Impairment, analisando se a concentração dos direitos de controle tem alguma relação sobre a evidenciação das exigências.

Sendo assim, na presente pesquisa a concentração acionária foi categorizada em duas classes segundo o grau de propriedade, as quais foram adaptadas dos estudos de Pedersen e Thomsen (1997 apud BARBOSA et al., 2014), que são: - Dominante: quando o maior acionista detém entre $30 \%$ e $50 \%$ do controle; e - Majoritário: quando o maior acionista detém mais de $50 \%$ do controle. As informações foram encontradas no site da CVM, onde estão disponíveis os formulários de referência das empresas controle. Foi considerada a soma do percentual das ações ordinárias para definir o tipo de controle acionário de cada companhia.

Na Figura 2, pode-se observar que cada empresa da amostra é comandada por um controle acionário diferente, o Banco Bradesco S.A. é conduzido pelo dominante, em que suas ações são distribuídas e controladas entre a Fundação Bradesco (17\%), NCF Participações S.A. (8\%), e Cidade de Deus Cia Cial Participações (49\%), não podendo nenhum acionista controlar mais que outro. Diferentemente do que ocorre com a companhia Gerdau S.A., a qual pertence ao controle acionário majoritário, com a Metalúrgica Gerdau S.A. com uma média de 77,83\% das ações durante os seis anos analisados, possuindo assim o poder de determinar a grande parte das decisões da companhia. 


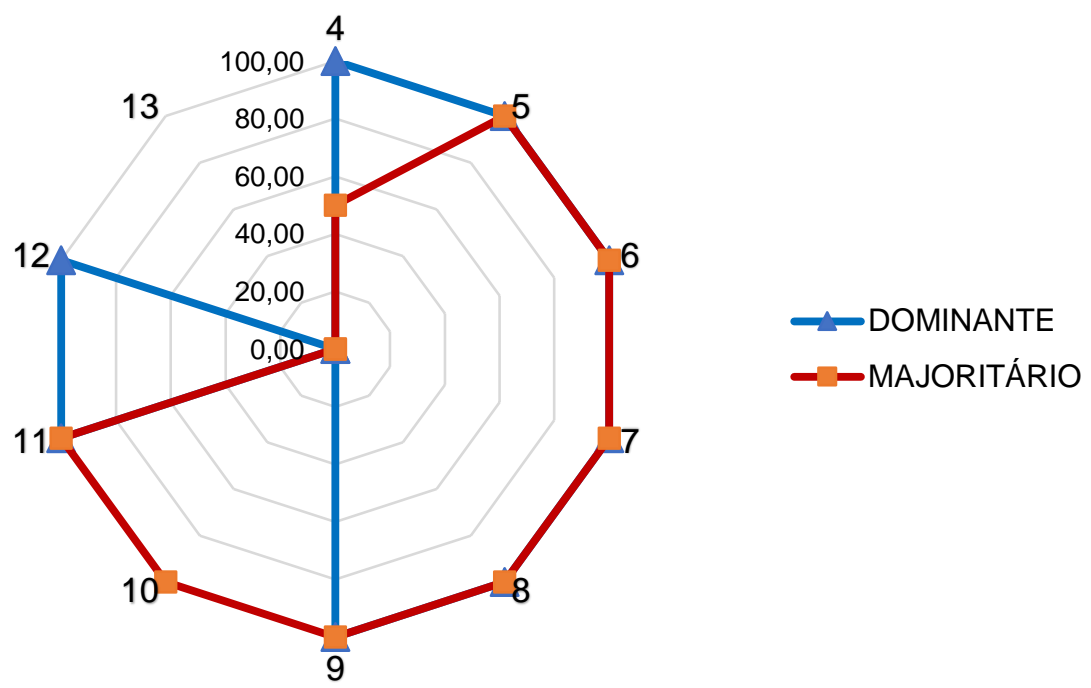

Figura 2. Percentual de divulgação vesus características do controle acionário

(2011-2016).

Fonte: Elaborada pela autora (2018)

A companhia com controle majoritário é a que menos divulgou as exigências da métrica, deixando de evidenciar o item 4 (base de cálculo) em metade dos anos estudados e o item 12 (os reflexos decorrentes de uma possível mudança na premissa-chave) em nenhum dos anos, já a companhia que possui característica de controle dominante, divulgou mais itens em relação à anterior, deixando de especificar o período (em anos) sobre o qual a administração projetou o fluxo de caixa (item 10) em todos os períodos. Contudo, observa-se que, independentemente do ano e da concentração acionaria o valor contábil do goodwill alocado à Unidade Geradora de Caixa, discriminado como item 13, foi o único item que não foi divulgado por nenhuma das companhias durante todos os períodos em análise.

\section{Considerações Finais}

Esta pesquisa pretendeu dar continuidade ao estudo de Barbosa et al. (2014), tendo como objetivo principal verificar o nível de divulgação das informações sobre o teste de Impairment no goodwill das empresas brasileiras de capital aberto, listadas na "Global 2000" pela revista eletrônica Forbes, no período de 2011 a 2016, em relação as exigências descritas e obrigatórias do CPC 01.

Para tanto, analisou-se as demonstrações contábeis no grupo de ativo intangível extraídas do site da Comissão de Valores Mobiliários. Sendo constituída inicialmente uma 
amostra das empresas que estão listadas no ranking durante todos os anos (de 2011 a 2016) e que possuem registro ativo nos seis anos descritos, o qual totalizaram 13. Contudo, restaram apenas duas companhias que apresentaram todos os requisitos solicitados, Bradesco S.A. e Gerdau S.A. Após a captação de dados, foi feita uma análise nas empresas que realizaram o reconhecimento de perda por desvalorização em relação aos itens verificados das exigências obrigatórias para divulgação do teste de Impairment no goodwill, de acordo com o CPC 01 (R1).

Os principais resultados demostraram uma divulgação positiva da grande maioria dos itens evidenciados durante os seis anos, com um número maior de exigências sobre o teste no último triênio. As companhias retrataram um percentual coeficiente de variação homogêneo, ou seja, houve pouca dispersão dos valores durante os anos, constatando-se uma evidenciação de média $80 \%$ das informações exigidas quanto ao teste de Impairment, de acordo com os itens da métrica designados.

Adicionalmente, verificou-se a proporção do goodwill no grupo intangível e no ativo total, onde a GerdauS.A. constatou que seu GI é formado basicamente pelo ágio por expectativa de rentabilidade futura, contudo ainda apresentando uma baixa representatividade do goodwill no ativo total. Ao contrário da Bradesco S.A. que não apresenta esse ágio em seu balanço nos anos analisados.

Os resultados demonstram ainda uma concentração acionária, dominante e a majoritária entre as empresas analisadas, comprovando que quando o poder de controle é em torno de um grande acionista, a empresa com concentração majoritária é a que menos divulga as exigências do CPC 01, enfatizando o menor nível de divulgação do teste de Impairment nas empresas com concentração acionária.

Este trabalho, de maneira geral, confirma os estudos realizados por Barbosa et al. (2014) de que, ao longo do tempo, as empresas tem aumentado o percentual de itens evidenciados, não significando dizer que as empresas ampliaram as informações em termos de conteúdo, pois seguiram igualmente durante todos os anos a quantidade apresentada. Porém, com uma evolução considerável nos anos de 2009 à 2016 se comparado os dois trabalhos em relação a antes de depois da obrigatoriedade da norma.

A contribuição desta pesquisa está em apresentar como fonte de estudo para a contabilidade societária, instrumento de apoio para uma melhor compreensão dos pronunciamentos técnicos contábeis, CPC 01, CPC 04 e CPC 15, decorrentes das alterações contábeis significativas com a introdução de conceitos sobre o Impairment a partir da 
divulgação da Lei 11.638/07 no Brasil. Como também, destacar a importância da realização do teste de recuperabilidade de ativos para as empresas, esclarecendo o tratamento contábil relacionado a evidenciação e identificação dos benefícios futuros logo após o seu reconhecimento inicial, contribuindo para a melhoria da qualidade da informação contábil divulgada para os investidores do mercado de capitais.

Como limitação deste estudo, destaca-se a quantidade restrita de empresas que apresentam o Impairment test em suas demonstrações nos anos selecionados, listadas na revista eletrônica Forbes, dificultando uma maior análise e comparação entre as companhias, limitando assim informações diversificadas para a presente pesquisa.

Para estudos futuros, indica-se: ampliar a amostra, acrescentando outras companhias listadas na BM\&FBovespa, além da ampliação do período analisado. Seria interessante utilizar outras métricas para determinação do índice de divulgação, tendo por base as exigências normativas contábeis internacionais com um estudo comparativo entre empresas de diversos segmentos econômicos.

\section{Referências}

ALBANI, P. C.; ALMEIDA, J. E. F. Teste de Impairment de ativos: análise comparativa da evidenciação das companhias abertas listadas no novo mercado por setor da economia e auditoria. Anais do Congresso USP de Iniciação Científica em Contabilidade. São Paulo-SP, Brasil, 9, 2012.

AVELINO, B. C.; PINHEIRO, L. E. T.; LAMOUNIER, W. M. Evidenciação de ativos intangíveis: estudo empírico em companhias abertas. Revista de Contabilidade e Organizações, 6(14), pp. 22-45, v. 6, n. 14, p. 23-45, jan./abr., 2012.

BARBOSA, J. S.; CONSONI, S.; SCHERER, L. M.; CLEMENTE, A. Impairment no Goodwill: uma Análise Baseada na Divulgação Contábil. Revista de Educação e Pesquisa em Contabilidade Brasília, v. 8, n. 2, art. 3, p. 159-179, abr./jun. 2014.

BIACHI, C. R. C. D.; MONTI, M. P.; REINA, D.; REINA, D. R. M.; HEHR, D. A. Evidenciação do impairment test: análise das empresas pertencentes ao índice IBrX-100. Revista Mineira de Contabilidade, v. 16, n. 1, art. 3, p. 27-38, jan./abr., 2015.

CAVALINHOS, P.; CARREIRA, F. O impacto do goodwill nos resultados. Revista Universo Contábil, ISSN 1809-3337, Blumenau, v. 11, n. 2, p. 196-210, abr./jun., 2015.

CPC. Comitê de Pronunciamentos Contábeis, Brasília, 2010. CPC 01 (R1) - Redução ao Valor Recuperável de Ativos. Disponível em <http://http://www.cpc.org.br/CPC >. Acesso em 10 fev, 2018. 
CPC. Comitê de Pronunciamentos Contábeis, Brasília, 2010. CPC 04 (R1) - Ativo Intangível. Disponível em <http://http://www.cpc.org.br/CPC >. Acesso em 10 fev, 2018.

CPC. Comitê de Pronunciamentos Contábeis, Brasília, 2011. CPC 15 (R1) - Combinação de Negócios. Disponível em <http://http://www.cpc.org.br/CPC >. Acesso em 10 fev, 2018.

CVM. Comissão de Valores Mobiliários (2007). Ofício-Circular/CVM/SNC/SEP n. 01/2007. Disponível em <http://www.cvm.gov.br/port/atos/oficios/OFICIO-CIRCULAR-CVM-SNCSEP-01_2007.asp. > Acesso em 05 mar, 2018.

DUTRA, Marcelo Haendchen; BORBA, José Alonso Borba; SOUZA, Maíra Melo de. Uma Verificação das Informações sobre o Impairment Test nas Demonstrações Financeiras Padronizadas (CVM) e no Relatório 20-F (SEC) das Empresas Brasileiras que Negociam ADR's na bolsa de valores. In: $2^{\circ}$ CONGRESSO UFSC DE CONTROLADORIA E FINANÇAS. Florianópolis/SC: Editora da UFSC, 2008.

FORBES. Revista Eletrônica (2011). GLOBAL 2000. Disponível em <https://www.forbes.com/2011/04/20/global-2000-11-ethodology.html\#f4ed2a32a225 > Acesso em $10 \mathrm{Fev}, 2018$.

GOMES, D. A. C.; SANTIAGO, W. P.; SANTOS, I. O.; FEITOSA, M. N. Impairment no goodwill: evidenciação contábil das empresas do 'Novo Mercado'. Revista Mineira de Contabilidade, v. 18, n. 3, art. 2, p. 16-26, set./dez., 2017.

MACHADO, E. A., CRUZ, A. P C., TAKAMATSU, R. T.; LIMA, G. A. S. F. Evidencias de disclosure de valor recuperável de ativos em firmas listadas no mercado acionário brasileiro. Revista Universo Contábil. 9(1), pp. 86-103, 2013.

MARTINS, E. Contribuição à avaliação do ativo intangível. Tese de Doutoramento, Faculdade de economia, administração e contabilidade da Universidade de São Paulo. 1972.

MARTINS, E. Goodwill: uma análise dos conceitos utilizados em trabalhos científicos. Revista Contabilidade \& Finanças, USP, São Paulo, v. 21, n. 52, janeiro/abril 2010.

MAZZIONI, S.; POLITELO, L.; MOREIRA, W. J.; KLANN, R. C. Fatores determinantes na evidenciação da redução ao valor recuperável de ativos (impairment test) em empresas listadas na Bm\&Fbovespa. Revista de Administração e Contabilidade da Unisinos 11(4):276-291, outubro/dezembro 2014.

NAKAYAMA, W. K.; SALOTTI, B. M. Fatores Determinantes do Nível de Divulgação de Informações sobre Combinações de Negócios com a Entrada em Vigor do Pronunciamento Técnico CPC 15. Revista Contabilidade \& Finanças - USP. São Paulo, v. 25, n. 66, p. 267 280, set./out./nov./dez. 2014.

PRESIDÊNCIA DA REPÚBLICA. Lei no 11.638, de 28 de Dezembro de 2007. Disponível em <http://www.planalto.gov.br/ccivil_03/_Ato2007-2010/2007/Lei/L11638.htm >. Acesso em 10 fev, 2018.

REIS, A. de O.; ANJOS, D. A.; SEDIYAMA, G. A. S.; LÉLIS, D. L. M. Disclosure da recuperabilidade do valor do ativo imobilizado: análise no setor siderúrgico brasileiro. Revista Ambiente Contábil, Natal - RN, v. 5. n. 2 p. 37-52, jul./dez. 2013. 
SCHMIDT, P.; SANTOS, J. L. Avaliação de ativos intangíveis. 2. ed. São Paulo: Atlas. 2009.

SMITH, M. S. J.; FERRAREZI, M. A. D.; CIA, J. N. de S. Impairment-obrigatoriedade ou estratégia: 0 caso de uma "sociedade Ltda.". In: $2^{\circ}$ CONGRESSO UFSC CONTROLADORIA E FINANÇAS, 2008, Florianópolis. Anais... Florianópolis: UFSC, 2008. CD-ROM.

SOUZA, M. M. Perda no valor recuperável de ativos: fatores explicativos do nível de evidenciação das empresas de capital aberto brasileiras. Dissertação de Mestrado, Universidade Federal de Santa Catarina, Florianópolis, SC, Brasil, 2011.

SOUZA, Maíra Melo de; BORBA, José Alonso; ZANDONAI, Fabiana. Evidenciação da perda no valor recuperável de ativos nas demonstrações contábeis: uma verificação nas empresas de capital aberto brasileiras. Revista Contabilidade Vista \& Revista, 22(2), pp.67-91, 2011.

TAVARES, M. F. N.; FILHO, J. F. R.; LOPES, J. E. G.; VASCONCELOS, M. T. C.; PEDERNEIRAS, M. M. M. Um estudo sobre o nível de conformidade dos setores classificados pela Bovespa com o CPC 01-Redução ao valor recuperável de ativos. Sociedade, Contabilidade e Gestão, v. 5, n. 1, 2010.

VIEIRA, L. B.; BRITO, S. S.; SANTANA, J. R. B.; SANCHES, S. L. R.; GALDAMEZ, E. V. C. Reflexo das operações de fusões e aquisições nos indicadores financeiros das empresas brasileiras de capital aberto. REGE - Revista de Gestão - USP. São Pulo, n.24, P. 235-246, mai. 2017.

VOGT, M.; PLETSCH, C. S.; MORÁS, V. R.; KLANN, R. C. Determinantes do Reconhecimento das Perdas por Impairment do Goodwill*. Revista Contabilidade \& Finanças - USP. São Paulo, v. 27, n. 72, p. 349-362, set./out./nov./dez. 2016.

ZANDONAI, F.; BORBA, J. A. O que dizem os achados das pesquisas empíricas sobre o teste de impairment: uma análise dos journals em língua inglesa. Contabilidade, Gestão e Governança, v. 12, n. 1, p. 24-34. Jan/abr. 2009.

\section{Como citar este artigo (Formato ABNT):}

MENEZES, Nera Ingridy Silva; LIMA FILHO, Raimundo Nonato. Impairment no Goodwill: Uma Análise Baseada na Divulgação Contábil de Empresas Brasileiras Listadas pela Revista Eletrônica Forbes. Id on Line Rev.Mult. Psic., 2019, vol.13, n.43, p. 698-716. ISSN: 1981-1179.

Recebido: 21/11/2018;

Aceito: 07/12/2018 